\title{
Satisfaction analysis of patients with single implant treatments based on a questionnaire survey
}

This article was published in the following Dove Press journal:

Patient Preference and Adherence

\section{Heng Dong ${ }^{1, *}$ \\ $\mathrm{Na}$ Zhou',* \\ Hui Liu',* \\ Haohao Huang ${ }^{2}$ \\ Guangwen Yang' \\ Li Chen' \\ Meng Ding ${ }^{3}$ \\ Yongbin Mou'}

'Department of Oral Implantology, Nanjing Stomatological Hospital, Medical School of Nanjing University, Nanjing, Jiangsu, People's Republic of China; ${ }^{2}$ Department of Oral and Maxillofacial Surgery, Nanjing Stomatological Hospital, Medical School of Nanjing University, Nanjing, Jiangsu, People's Republic of China; ${ }^{3}$ Nanjing Stomatological Hospital, Medical School of Nanjing University, Nanjing, Jiangsu, People's Republic of China

*These authors contributed equally to this work
Correspondence: Yongbin Mou; Meng

Ding

Department of Research Service, Nanjing Stomatological Hospital, Medical School of Nanjing University, \#30 Zhongyang Road, Nanjing 210008, People's Republic of China

Tel +862583620236

Fax +862583620202

Email yongbinmou@163.com; xzdingmeng@163.com
Background: The factors influencing satisfaction of the patients with implant treatments are still unclear. This study aims to evaluate the patients' satisfaction and to identify influencing factors, which will improve the medical quality of oral implantology.

Materials and methods: Patients who lost single teeth and received implant treatments were enrolled in Nanjing Stomatological Hospital between February 2016 and March 2018. A questionnaire survey was performed to assess patient satisfaction and data were collected at four time points. Information included gender, age, educational level, application of bone augmentation, type of prosthetic restoration, period of teeth loss, dentist qualification, and tooth position. Meanwhile, the satisfaction of the patients was evaluated by visual analog scale.

Results: A total of 373 patients completed the questionnaires. The mean of overall satisfaction score was $69.05 \pm 7.10$. Lower overall satisfaction score was found in patients who received bone augmentation $(P<0.001)$ and those with a longer period of teeth loss $(P<0.05)$. In the bone augmentation group, the elements of pain and complication were significantly associated with a decrease in the median satisfaction score $(P<0.001)$, and a similar result was obtained form the duration of operative time and healing response $(P<0.001)$. On the other hand, the satisfaction scores for elements including the duration of operative time and healing response $(P<0.05)$, aesthetics and psychology $(P<0.05)$, and chewing function $(P<0.05)$ decreased with an extended period of teeth loss. Meanwhile, over half of respondents were more concerned about the survival time $(40.70 \%)$ and success rate (20.49\%) of implants.

Conclusion: Bone augmentation and the period of teeth loss are negative factors affecting patient satisfaction, and the success rate and survival time of implants are considerable aspects for patients. It is essential to raise general awareness of oral hygiene and optimize the dental implant therapeutic process.

Keywords: dental implant, dental satisfaction, bone augmentation, period of teeth loss

\section{Introduction}

Dental implant-supported prosthesis is known as the nearest equivalent replacement to the natural tooth and has been proven to have a predictable and reliable therapeutic effect for missing teeth. ${ }^{1}$ According to the European Association for Osseointegration consensus conference in 2015, replacement with a single implantsupported crown was more cost-effective compared with a fixed bridge or removable partial denture. ${ }^{2}$ As a widely accepted therapy for the functional rehabilitation of dentition defect, substantial numbers of studies have confirmed the high survival rates of fixed implant-supported prosthesis. ${ }^{3-5}$ However, nonfunctional parameters 
such as aesthetic outcomes and patient satisfaction were underexposed. Patient satisfaction after treatment with implants was prone to be affected by the disparity between extremely high expectations and the the final outcomes. ${ }^{6}$ With the increasing popularization of dental implant awareness, the shortcomings of implant treatment become more easily to understood or accepted by patients. Nonetheless, it was difficult to balance patients' expectation and the dentists' evaluation of occlusal function as the specific propaganda and education for patients were limited. The priority of the general therapeutic plan was the preservation of implants and the prevention of periimplantitis, while patients were more prone to take comfort and aesthetics into consideration. ${ }^{7}$ Therefore, it is crucial to investigate the factors which could affect patient satisfaction and the implant treatment plans supported by dentists.

Although implant-relevant pain and inflammation could reduce patient satisfaction in an advanced stage of periimplantitis, ${ }^{8}$ the assessment of actual feeling for asymptomatic patients after implant treatment was still a challenge. With the absence of periodontal ligament feeling, the specific feeling and chewing efficiency of the dental implants was different compared with natural teeth. ${ }^{9}$ In addition, the implant placement surgeries under local anesthesia bring operative trauma to some extent, and the patients who received bone augmentation during dental implant surgery have an even longer operative time and a higher risk of complications. ${ }^{10}$ However, the relationship between influencing factors and real-time feeling in the implant therapeutic process was rarely investigated. Of note, complications, masticatory function, and aesthetics are also correlated factors affecting comfortable perception and satisfaction of patients. Like most surgeries, pain, swelling, and length of operative time could compromise patients' experience during implant surgeries. ${ }^{11,12}$ Moreover, the job competency and the attitude of dentists have significant influences on patients' first impression. Exploring the most relevant factors is essential to improve patient satisfaction, which could subsequently lead to better compliance during dental implant treatment.

Therefore, it is urgent to investigate the influencing factors of patients' satisfaction, which can help us to optimize the implant therapeutic process, improve the relationship between dentists and patients, and reduce the occurrence of medical disputes. Overall, the aim of this study was to evaluate the clinical influencing factors during the therapeutic process and improve the clinical experience properly.

\section{Patients and methods Inclusion and exclusion criteria of participants}

Inclusion criteria: all patients were at least 18 years of age with single tooth loss for at least 3 months. The patients received single implant treatments between February 2016 and March 2018 in the Oral Implantology Department of Nanjing Stomatological Hospital (NSH), Medical School of Nanjing University. Patients had bone-level implants inserted by a 2-step surgical procedure and agreed to provide informed written consent and timely follow-up in the study plan. Exclusion criteria: patients who had received implant treatment before this study and who were unable to comply with all study procedures, such as if they had severe periodontitis, systemic diseases, history of chemotherapy, head and neck radiotherapy, smoking history, and needed immediate implant placement, were excluded. Patients matching the inclusion criteria numbered 450, and, finally, a total of 373 participants who completed questionnaires were enrolled and their data were evaluated in this study.

\section{Implant surgery protocol}

Dental implant surgeries were conducted based on the protocols of different implant systems, after routine blood test, radiographic screening, and periodontal treatment. Briefly, patients were instructed to gargle with the iodophor detergent for $1 \mathrm{~min}$ and anesthetized labially by local infiltration injections. Then, plant holes were prepared using graduated diameters after the flap surgeries. When required, bone augmentation was performed to produce enough bone mass to place the implant simultaneously. Thereafter, all patients were asked to use compound chlorhexidine gargle daily within the 14 postoperative days and take antibiotics for at least 3 days after surgeries. In general, the healing time before ultimate restoration was 4 months for patients without bone augmentation procedures, and 6 months for those with bone augmentation procedures simultaneously. After the osseointegration period, the implant prostheses were loaded and the results were presented according to radiological evaluation and a 1-year follow-up. During the entire treatment course, patients were asked to complete the questionnaires at preoperation (Phase 1), postoperation (Phase 2), crown completion (Phase 3), and follow-up (Phase 4), respectively.

\section{Ethics}

This study has been approved by the Institutional Review Board of NSH, Medical School of Nanjing 
University. All participants entered the study voluntarily, following an explanation of its purpose. Each patient signed informed consent on the first page of the questionnaire, and the privacy of the patients was ensured.

\section{Questionnaire design}

The questionnaire covers participants' information including name, gender, age, educational level, and telephone number and their satisfaction score based on a visual analog scale of 1-5. According to the Oral Health Impact Profile-14 questionnaire, ${ }^{13}$ the oral implant impact profile questionnaire (OIIP-Q) was reorganized to contain 15 questions (Q1-Q15) related to satisfaction with the dental implant. All participants were asked to disclose the level of impact on visual analog scales where ' 1 ' $=$ unsatisfaction to ' 5 ' $=$ satisfaction. There was an open-ended question at the bottom of the OIIP-Q reported in Phase 4, which was "What was the most concerning aspect that affected your satisfaction in the implant treatment?" The procedure of analysis is shown in Figure 1.

\section{Statistical analysis}

The data were summarized and analyzed using SPSS software (version 19.0; IBM Corporation, Armonk, NY, USA). Descriptive statistics were used for the sociodemographic characteristic data. Scores for the OIIP-Q were presented as mean $\pm \mathrm{SD}$. Factor analysis was also conducted by Kaiser-Meyer-Olkin and Bartlett's tests. Independent sample $t$-tests and one-way ANOVA were used to compare differences between different groups. The significant level was confirmed by $P<0.05$.

\section{Results}

\section{Sociodemographic characteristics and distribution of population}

The characteristics of the participants are shown in Table 1. From a total of 450 respondents, 178 males and 195 females agreed and completed the OIIP-Q, and the response rate was $82.89 \%$. The mean age of participants was $43.66 \pm 14.33$ years. The percentages of participants were $50.9 \%$ over 45 years old, $29.76 \%$ between 30 and 45 years old, and $19.30 \%$ less than 30 years old. Of the total 373 participants, there were 55

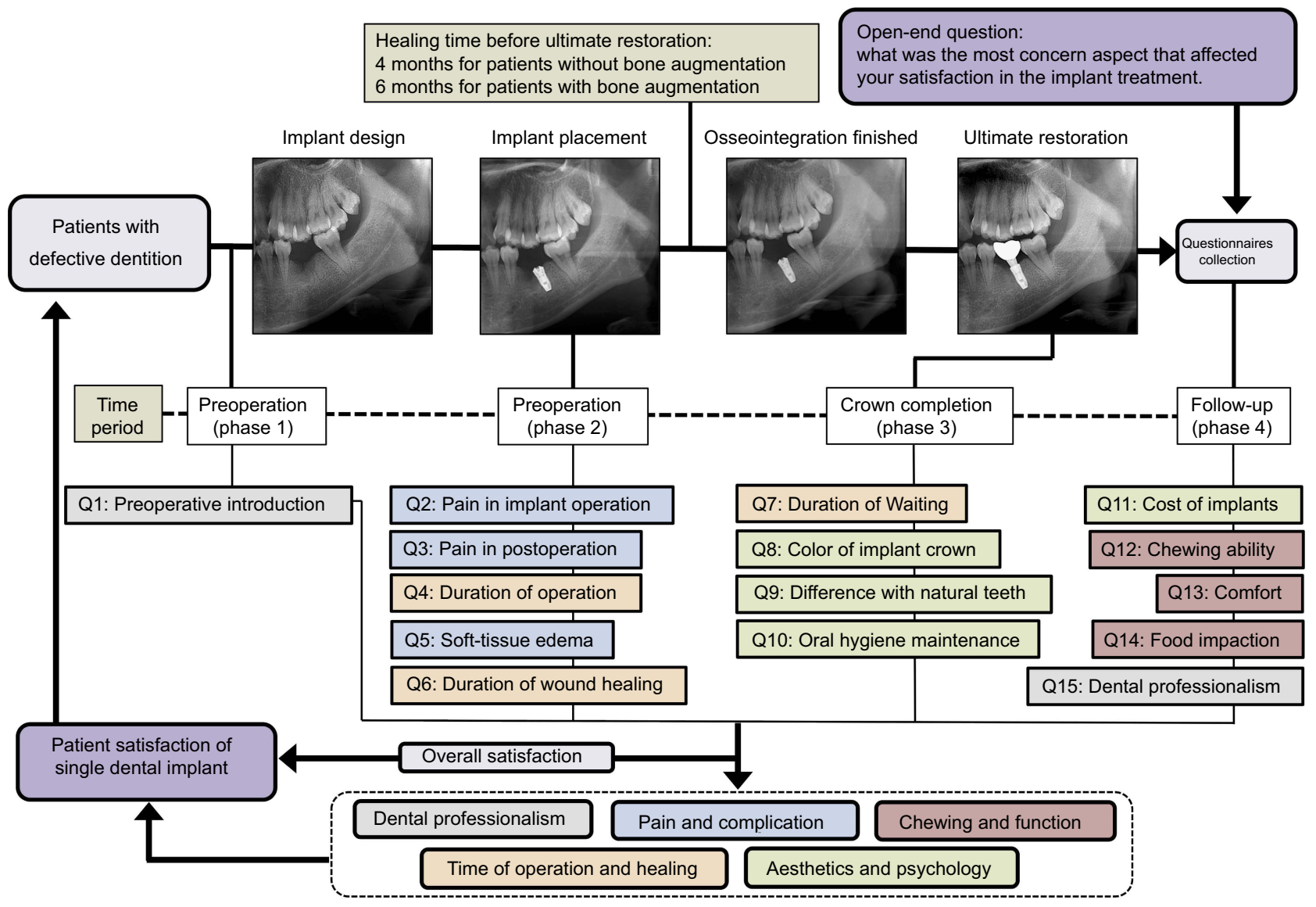

Figure I Flow chart of the factors for patient satisfaction. 
Table I Demographic variables studied according to simple count

\begin{tabular}{|c|c|}
\hline Variable & Frequency [n (\%)] \\
\hline \multicolumn{2}{|l|}{ Gender } \\
\hline Males & 178 (47.72) \\
\hline Females & $195(52.28)$ \\
\hline \multicolumn{2}{|l|}{ Age (years) } \\
\hline $18-29$ & $72(19.30)$ \\
\hline $30-45$ & III (29.76) \\
\hline$>45$ & $190(50.94)$ \\
\hline Age (mean $\pm S D)$ & $43.66 \pm 14.33$ \\
\hline \multicolumn{2}{|l|}{ Educational level } \\
\hline Professional education or below & $162(43.43)$ \\
\hline Bachelor & I56 (4I.82) \\
\hline Postgraduate & $55(14.75)$ \\
\hline \multicolumn{2}{|l|}{ Bone augmentation } \\
\hline With & $47(12.60)$ \\
\hline Without & $326(87.40)$ \\
\hline \multicolumn{2}{|l|}{ Type of prosthetic restoration } \\
\hline All-ceramic & $210(56.30)$ \\
\hline PFM & $163(43.70)$ \\
\hline \multicolumn{2}{|l|}{ Period of teeth loss } \\
\hline$<1$ year & $75(20.11)$ \\
\hline $\mathrm{I}-2$ years & I84 (49.33) \\
\hline$>2$ years & 114 (30.56) \\
\hline \multicolumn{2}{|l|}{ Qualifications of dentist } \\
\hline Junior dentists & $118(31.64)$ \\
\hline Senior dentists & $255(68.36)$ \\
\hline \multicolumn{2}{|l|}{ Implant position } \\
\hline Maxillary anterior teeth & 7I (18.60) \\
\hline Mandible anterior teeth & $3(0.8 \mathrm{I})$ \\
\hline Maxillary premolar & $45(12.13)$ \\
\hline Mandible premolar & $20(5.39)$ \\
\hline Maxillary molar & $79(21.29)$ \\
\hline Mandible molar & I55 (4I.78) \\
\hline
\end{tabular}

Notes: $\mathrm{n}=373$ (77 of 450 respondents did not complete the questionnaire).

postgraduates (14.75\%), 156 college graduates $(41.82 \%)$, and 162 below the level of professional education (43.43\%). With regard to their implant operation, the rate of patients with bone augmentation was less than those without $(12.60 \%$ vs $87.40 \%)$. As for the type of prosthetic restoration, 210 participants $(56.30 \%)$ selected all-ceramic crowns and the others $(43.70 \%)$ chose porcelain-fused-to-metal crowns (PFM). Regarding the period of teeth loss, 75 patients $(20.11 \%)$ were less than 1 year. In addition, 118 patients (31.64\%) were assigned to junior dentists and $255(68.36 \%)$ to senior dentists for treatment. According to implant positions, there were only minor implants $(0.81 \%)$ placed in the mandible anterior area, possibly owing to fewer single implants in this area.

\section{Fifteen-item questionnaire (OIIP-Q) for the assessment of patient satisfaction}

Nearly all items regarding the level of patient satisfaction with implant treatment were scored positive (mean scores $>4$ ). As shown in Table 2, the mean satisfaction score ranged from 4.44 to 4.75 in the 15 items, suggesting that single implant treatments for missing teeth met the expectations of patients. The highest score was presented by those who were given the preoperative introduction by dentists (4.75 \pm 0.56$)$ in NSH as they could enjoy excellent preoperative evaluation and education of dental implants. The dental professionalism score $(4.74 \pm 0.54)$ meant favorable dental professional literacy. The lowest scores were given from those with foreign body sensation of implants compared with their natural teeth $(4.44 \pm 0.77)$, indicating that there was still a feeling distinction between dental implants and natural teeth. In addition to what was mentioned above, the other two higher satisfied items were the comfortable feeling with dental implants $(4.69 \pm 0.65)$ and restoration of chewing ability $(4.68 \pm 0.65)$. These data demonstrated that dental implant treatment has become a preferable choice for the patients with missing teeth. In contrast, the two unsatisfied items, in order, were soft-tissue edema (4.52 \pm 0.70$)$ and postoperative pain ( $4.52 \pm 0.73)$, suggesting that postoperative reactions were the major uncomfortable factors. The similar inquiry for the feeling of pain during the implant operation (4.64 \pm 0.65$)$ got a higher satisfaction score compared with that of postoperation and softtissue edema, meaning the local anesthesia technology was effective in dental implant surgery. To check the internal consistency of the statements comprising items of all questions, Cronbach's alpha was tested and the value was 0.93 , indicating that all questions have excellent reliabilities. The Kaiser-Meyer-Olkin measure of sampling adequacy was 0.955, and Bartlett's test of sphericity was significant $\left(\chi^{2}=2,872.499\right.$, degrees of freedom=105, $\left.P<0.001\right)$, implying high appropriateness in the satisfaction score with various aspects of implant treatment. Additionally, the mean \pm SD of overall satisfaction was $69.96 \pm 7.10$.

\section{Variables affecting implant overall satisfaction scores of patients}

As shown in Table 3, the overall satisfaction score of patients with bone augmentation was lower than that of 
Table 2 Oral implant impact profile questionnaire pertaining to satisfaction score with various aspects of implants $(n=373)$

\begin{tabular}{|c|c|c|}
\hline Time period & Item & Mean \pm SD \\
\hline Preoperation (Phase I) & QI. How do you feel with the introduction by dentists before treatment with implants? & $4.75 \pm 0.56$ \\
\hline Postoperation (Phase 2) & $\begin{array}{l}\text { Q2. How do you feel pain during the implant operation? } \\
\text { Q3. How do you feel with postoperative pain? } \\
\text { Q4. How do you feel with the duration of operative time? } \\
\text { Q5. How do you feel with soft-tissue edema? } \\
\text { Q6. How do you feel with the duration of wound healing? }\end{array}$ & $\begin{array}{l}4.64 \pm 0.65 \\
4.52 \pm 0.73 \\
4.56 \pm 0.68 \\
4.52 \pm 0.70 \\
4.60 \pm 0.70\end{array}$ \\
\hline Crown completion (Phase 3) & $\begin{array}{l}\text { Q7. How do you feel with the duration of waiting for the final restoration? } \\
\text { Q8. How do you feel with the color of your implant crown? } \\
\text { Q9. How do you feel with the implants compared with natural teeth? } \\
\text { Q10. How do you feel with the trouble of oral hygiene maintenance? }\end{array}$ & $\begin{array}{l}4.57 \pm 0.69 \\
4.54 \pm 0.68 \\
4.44 \pm 0.77 \\
4.60 \pm 0.68\end{array}$ \\
\hline Follow-up (Phase 4) & $\begin{array}{l}\text { QII. How do you feel with the cost of implant treatment? } \\
\text { QI2. How do you feel with chewing ability? } \\
\text { Q13. How do you feel comfortable with implant teeth? } \\
\text { Q14. How do you feel with food impaction? } \\
\text { QI5. How do you feel with dental professionalism? }\end{array}$ & $\begin{array}{l}4.56 \pm 0.65 \\
4.68 \pm 0.65 \\
4.69 \pm 0.65 \\
4.64 \pm 0.74 \\
4.74 \pm 0.54\end{array}$ \\
\hline \multicolumn{2}{|l|}{ Overall satisfaction } & $69.05 \pm 7.10$ \\
\hline
\end{tabular}

those without, and there was a significant difference between them $(P<0.001)$. However, there were no significant differences for gender, type of crown, and qualifications of dentists in overall satisfaction scores (all $P>0.05$ ). The result of one-way ANOVA demonstrated that the value of satisfaction score decreased with a longer period of teeth loss. Notably, the overall satisfaction score in patients with a shorter period of teeth loss $(<1$ year) was slightly higher compared with the other two groups $(P<0.05)$. However, the overall satisfaction scores for age, educational level, and implant position showed no significant differences in different groups (all $P>0.05$ ).

\section{Bone augmentation and period of teeth loss affecting patient satisfaction with dental implant treatment}

The more complicated procedure of bone augmentation and the movement of residual natural teeth in different periods of teeth loss are shown in Figure 2. According to the results shown in Table 3 , bone augmentation and the period of teeth loss were the correlative variables which affected the overall satisfaction score of patients with dental implant treatment. Moreover, in order to subdivide the elements influencing satisfaction, 15 questions were categorized according to the following elements: dental professionalism, pain and complication, duration of operation and healing, aesthetics and psychology, chewing and function. As shown in Table 4, there was a significant difference in pain and complications between the patients with bone augmentation and those without (11.80 \pm 1.46 vs $13.96 \pm 1.60, P<0.001)$, implying that the bone augmentation procedures have a great contribution to the decrease of satisfaction score. Similarly, a significant difference was observed in elements such as the duration of operative time and healing response. Notably, the satisfaction score for patients with bone augmentation was lower than those without (12.55 \pm 1.55 vs $13.90 \pm 1.61, P<0.001)$, meaning longer operating and healing time decrease the favorable impression of dental implant treatment. The result of oneway ANOVA demonstrated that there were three elements affected by the period of teeth loss: duration of operation and healing $(P<0.05)$, aesthetics and psychology $(P<0.05)$, and chewing and function $(P<0.05)$. It is noteworthy that the patient satisfaction score decreased with a prolonged period of teeth loss.

\section{The most concerning aspects of dental implant treatment}

In order to fully understand the most concerning aspects for patients with implant-supported single crowns, the open-ended question "what was the most concerning aspect that affectedyour satisfaction in the implant treatment?" was listed at the bottom of the OIIP-Q. The distribution of answer to the questions is showed in Figure 3, with most of the participants 
Table 3 Overall satisfaction score (questionnaire) of patients

\begin{tabular}{|c|c|c|c|}
\hline Variable & $\begin{array}{l}\text { Score } \\
\text { (mean } \pm S D)\end{array}$ & $t / F$ & $P$-value \\
\hline $\begin{array}{l}\text { Age group (years) } \\
\begin{array}{l}18-29 \\
30-45 \\
>45\end{array}\end{array}$ & $\begin{array}{l}69.58 \pm 5.85 \\
68.8 I \pm 8.16 \\
69.49 \pm 6.90\end{array}$ & $F=0.386$ & 0.680 \\
\hline $\begin{array}{c}\text { Gender } \\
\text { Male } \\
\text { Female }\end{array}$ & $\begin{array}{l}69.19 \pm 7.19 \\
69.42 \pm 7.05\end{array}$ & $t=-0.312$ & 0.755 \\
\hline $\begin{array}{l}\text { Bone augmentation } \\
\text { With } \\
\text { Without }\end{array}$ & $\begin{array}{l}66.13 \pm 5.93 \\
69.76 \pm 7.15\end{array}$ & $t=-3.322$ & $0.00 I^{*}$ \\
\hline $\begin{array}{l}\text { Type of crown } \\
\text { All-ceramic } \\
\text { PFM }\end{array}$ & $\begin{array}{l}69.23 \pm 6.61 \\
69.40 \pm 7.73\end{array}$ & $t=-0.233$ & 0.816 \\
\hline $\begin{array}{l}\text { Qualifications of } \\
\text { dentist } \\
\text { Junior dentists } \\
\text { Senior dentists }\end{array}$ & $\begin{array}{l}69.10 \pm 6.90 \\
69.40 \pm 7.21\end{array}$ & $t=0.376$ & 0.707 \\
\hline $\begin{array}{l}\text { Educational level } \\
\text { Professional education } \\
\text { or below } \\
\text { Bachelor } \\
\text { Postgraduate }\end{array}$ & $\begin{array}{l}69.38 \pm 6.95 \\
69.73 \pm 6.50 \\
67.91 \pm 8.96\end{array}$ & $F=I .343$ & 0.262 \\
\hline $\begin{array}{l}\text { Period of teeth loss } \\
\text { <1 year } \\
\text { I-2 years } \\
>2 \text { years }\end{array}$ & $\begin{array}{l}71.43 \pm 4.28 \\
68.95 \pm 7.65 \\
68.49 \pm 7.46\end{array}$ & $F=4.402$ & $0.013^{*}$ \\
\hline $\begin{array}{l}\text { Implant position } \\
\text { Anterior teeth } \\
\text { Premolar } \\
\text { Molar }\end{array}$ & $\begin{array}{l}69.49 \pm 4.31 \\
70.12 \pm 6.56 \\
69.31 \pm 7.11\end{array}$ & $F=0.647$ & 0.524 \\
\hline
\end{tabular}

Note: Independent sample $t$-tests and one-way ANOVA, ${ }^{*} P<0.05$ means statistical significance.

(40.70\%) concerned about the survival time of implants, hoping the dental implants could be permanent with good retention and resistance. Approximately $20.49 \%$ of the participants considered that the success rate of the implant treatment and $15.36 \%$ considered the mastication function was of great importance, respectively. A total of $10.24 \%$ of participants considered aesthetics as their principal concern, most of whom received single implants in the anterior position of jaws $(81.58 \%$ ), while only $8.63 \%$ of respondents thought food impaction was the most concerning aspect, and $4.58 \%$ answers covered the expenses, pronunciation, occlusion, and swallow function.

\section{Discussion}

Dental patient satisfaction is one of the important items for evaluating clinical services, ${ }^{14}$ so understanding and measuring its priority to the treatment appears to be essential for dentists to improve clinical outcomes. Usually, satisfactory patients have better compliance, the same as the rate of follow-up. Generally, a large proportion of treatments that patients received from dentists were tooth extraction, root canal treatment, and removable partial denture. ${ }^{15-17}$ However, with the development of implantology, dental implant treatment has become a more convenient treatment to restore missing teeth and improve the patients' quality of life. ${ }^{18}$ Despite the forms of studies assessing the extent of patient satisfaction varying in the implant therapeutic process, they were all mid-term and long-term evaluations. ${ }^{19,20}$ What matters most was that these forms may have a potential problem to ignore realtime feelings of patients. In order to enhance the comprehension of the implant satisfaction, both patient-related and implant-related factors were investigated in four phase within our questionnaire design. Thus, the most relevant factors contributing to dental implant satisfaction during different periods would be determined in our study.

It is well known that evaluation of dental implants includes many parameters, such as aesthetics, comfort, functionality, longevity, hygiene, presentation, and psychological satisfaction. ${ }^{21-23}$ Only patients with an implant-supported single crown by a 2 -step surgical procedure were enrolled in our study, as those with multiple defects need longer operative time, more complex restorations, and even more complicated bone augmentation were excluded. Besides, those who revealed extremely high satisfaction scores on immediately loaded implants because of the shorter curative time were also excluded. ${ }^{24}$ According to multiple factors in different periods of implant treatment, the OIIP-Q was designed. Based on the OIIP-Q, the lowest score was obtained for patients who insisted that the significant difference between dental implants and natural teeth was possibly due to the absence of the periodontal ligament and baroreceptors of implants. This indicated that patients were more prone to occlusal overloading during the usage period of implants. ${ }^{25}$ Although implantation had a lower pain level during bone and soft tissue manipulation compared with surgical impacted tooth removal or apicectomy, ${ }^{17}$ persistent postoperative pain and soft-tissue edema were important factors responsible for the reduction of patient satisfaction. In 
A

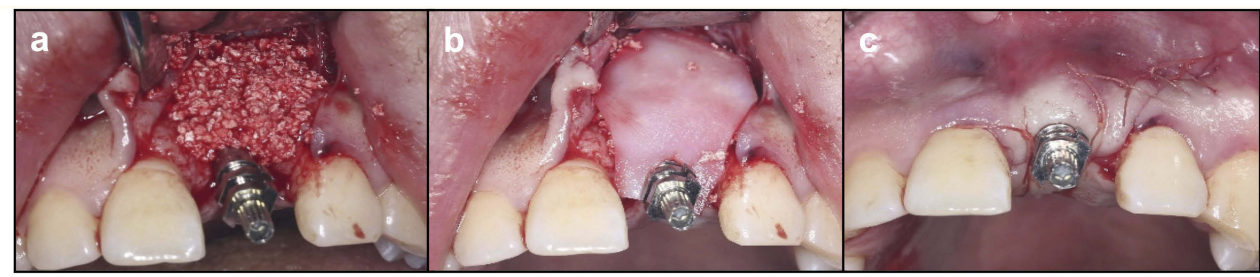

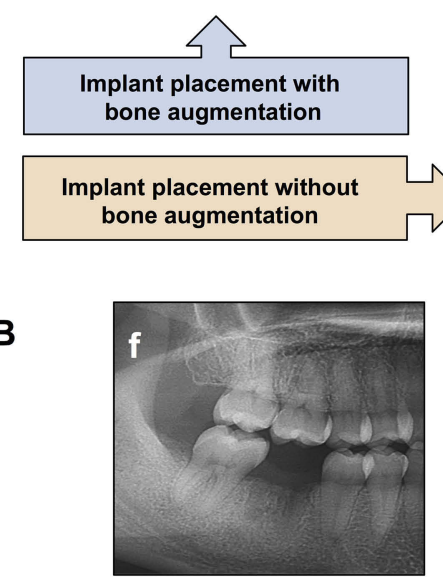

$<1$ year

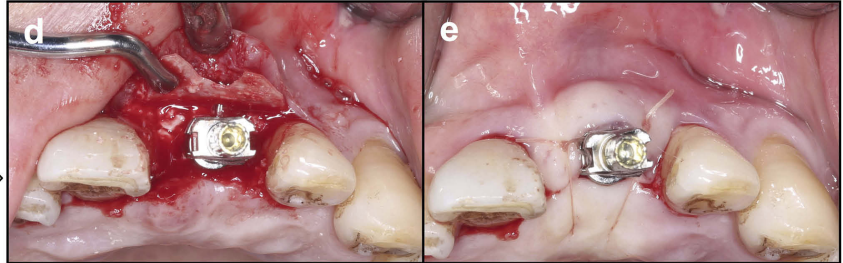

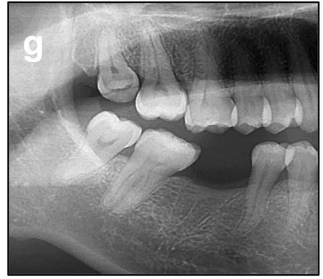

1 2 years

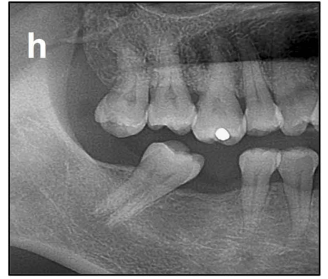

$>2$ years

Figure 2 The differences in the bone augmentation group and the period of teeth loss group. (A) Implant placement with (a, b, c) or without (d, e) bone augmentation. (B) Typical X-ray pictures of the period of teeth loss in different patients: $(f)$ the period of teeth loss was less than I year; $(g)$ the period of teeth loss was I-2 years, there was a tilting of adjacent teeth; and $(h)$ the period of teeth loss was more than 2 years, elongation of paired jaw teeth, tilting of adjacent teeth, and insufficient repair space are obviously shown.

order to eliminate discomfort during the surgical procedure, flapless implant insertion and computer-guided implant surgery were applied in some cases, which could help in reducing postoperative pain and edema, as well as the operative time. ${ }^{26-28}$ Thus, a minimally invasive and precise operation would be of considerable significance in dental implant treatment.

We also assessed the sociodemographic variations across the overall satisfaction score, as demonstrated by the results of univariate statistical analysis that bone augmentation and the period of teeth loss was directly related to overall satisfaction. For example, the less bone augmentation, the better feelings of pain and complication, and a more positive evaluation of the operation and healing time was positively related to the overall satisfaction score. In the past, bone augmentation was an essential method to acquire enough bone mass for an atrophic alveolar ridge. However, with the rapid development of implant surface technology inserting, a short implant without bone augmentation has also gained high success rates. ${ }^{29,30}$ On the other hand, some patients who need bone augmentation can choose internal sinus floor elevation with fewer traumas in the posterior maxilla. ${ }^{31}$ Meanwhile, patients with a shorter period of teeth loss were inclined to shorten the duration of operative time and healing and to restore the feeling of aesthetics and psychology as well as chewing function. Notably, loss of teeth has negative influences on alveolar bone preservation, causing a lack of alveolar ridge dimension and volumes in the vertical, horizontal, and transversal directions. ${ }^{3232}$ In addition, prolonged absence of teeth can lead to changes in the dentition, elongation of the paired jaw teeth, tilting of adjacent teeth, insufficient repair space, and retraction of the alveolar bone. Facing these adverse changes, dentists cannot but grind the adjacent or the paired jaw teeth. Accordingly, the final implants will produce frustrating outcomes such as food impaction and gingival recession. Nowadays, there are many ways to get information in the modern world. However, patients often acquire insufficient information regarding dental implants. ${ }^{33}$ Therefore, it is necessary to improve public awareness about the disadvantages of missing teeth through various ways, such as oral health education and stream media. What is more, it is preferable to apply technologies such as immediate implantation and extraction site preservation to reduce the alveolar bone loss. $^{34}$

Although many factors would affect satisfaction of patients who underwent reconstruction by implant treatment, with or without bone augmentation and the period of teeth loss seem to 
Table 4 Elements of satisfaction score analysis for bone augmentation and period of teeth loss variables

\begin{tabular}{|c|c|c|c|c|}
\hline Element of questions & Variable & Score (mean $\pm S D)$ & $\mathbf{t} / \mathbf{F}$ & $P$-value \\
\hline Dental professionalism (QI+QI5) & $\begin{array}{l}\text { Bone augmentation } \\
\text { With } \\
\text { Without } \\
\text { Period of teeth loss } \\
<1 \text { year } \\
\text { I-2 years } \\
>2 \text { years }\end{array}$ & $\begin{array}{l}9.44 \pm 0.80 \\
9.49 \pm 0.95 \\
9.71 \pm 0.59 \\
9.44 \pm 1.01 \\
9.40 \pm 0.95\end{array}$ & $\begin{array}{l}t=-0.289 \\
F=2.990\end{array}$ & $\begin{array}{l}0.773 \\
0.052\end{array}$ \\
\hline Pain and complication $\left(\mathrm{Q}^{2+Q 3+Q 5)}\right.$ & $\begin{array}{l}\text { Bone augmentation } \\
\text { With } \\
\text { Without } \\
\text { Period of teeth loss } \\
<\text { I year } \\
\text { I-2 years } \\
>2 \text { years }\end{array}$ & $\begin{array}{l}|1.80 \pm| .46 \\
|3.96 \pm| .60 \\
|4.06 \pm| .38 \\
|3.64 \pm| .76 \\
|3.5| \pm \mid .89\end{array}$ & $\begin{array}{l}t=-8.730 \\
F=2.402\end{array}$ & $\begin{array}{l}<0.00 \mid * \\
0.092\end{array}$ \\
\hline Duration of operation and healing $(\mathrm{Q} 4+\mathrm{Q} 6+\mathrm{Q} 7)$ & $\begin{array}{l}\text { Bone augmentation } \\
\text { With } \\
\text { Without } \\
\text { Period of teeth loss } \\
<\text { I year } \\
\text { I-2 years } \\
>2 \text { years }\end{array}$ & $\begin{array}{l}12.55 \pm 1.55 \\
|3.90 \pm| .6 \mid \\
14.19 \pm 1.23 \\
13.66 \pm \mid .74 \\
|3.55 \pm| .74\end{array}$ & $\begin{array}{l}t=-5.386 \\
F=3.818\end{array}$ & $\begin{array}{l}<0.00 I^{*} \\
0.023 *\end{array}$ \\
\hline Aesthetics and psychology (Q8+Q9+Q10+QII) & $\begin{array}{l}\text { Bone augmentation } \\
\text { With } \\
\text { Without } \\
\text { Period of teeth loss } \\
<\text { I year } \\
\text { I-2 years } \\
>2 \text { years }\end{array}$ & $\begin{array}{l}18.05 \pm 2.17 \\
18.15 \pm 2.17 \\
18.75 \pm 1.59 \\
18.01 \pm 2.30 \\
17.95 \pm 2.24\end{array}$ & $\begin{array}{l}t=-0.296 \\
F=3.752\end{array}$ & $\begin{array}{l}0.768 \\
\mathbf{0 . 0 2 4}\end{array}$ \\
\hline Chewing and function $(\mathrm{Q}|2+\mathrm{Q}| 3+\mathrm{Q} \mid 4)$ & $\begin{array}{l}\text { Bone augmentation } \\
\text { With } \\
\text { Without } \\
\text { Period of teeth loss } \\
<1 \text { year } \\
\text { I-2 years } \\
>2 \text { years }\end{array}$ & $\begin{array}{l}14.02 \pm 1.67 \\
14.00 \pm 1.73 \\
14.45 \pm 1.07 \\
13.93 \pm 1.84 \\
13.83 \pm 1.85\end{array}$ & $\begin{array}{l}t=0.062 \\
F=3.303\end{array}$ & $\begin{array}{l}0.951 \\
\text { 0.038* }\end{array}$ \\
\hline
\end{tabular}

Note: Independent sample $t$-tests and one-way ANOVA, $* P<0.05$ means statistical significance.

be more related. Besides, we still want to know the specific aspects of implant treatment that patients are mostly concerned about. At the end of the OIIP-Q, we designed an open-ended question and the results showed that the success rate and survival time of the implant took up a great proportion. Therefore, to ensure the success of implant surgery, a dentist should decrease the complications, reduce the peri-implantitis, and confirm the stability of the implants' osseointegration. In addition, the variables of mastication, phonetic, comfort use, and retention issues showed lower satisfaction in patients with implant-supported fixed partial dentures in a past study. ${ }^{35} \mathrm{In}$ our study, the variables of mastication function, aesthetic effect, and food impaction of patients who underwent dental implant treatment also occupied a medium degree of attentiveness. All of these results suggested that undesirable mastication, nonaesthetic crowns, and insufferable food impaction could cause discomfort and worries from patients. Thus, dentists should help patients in overcoming their worries which could cause stress and discomfort by rational implant design and humanistic care. 


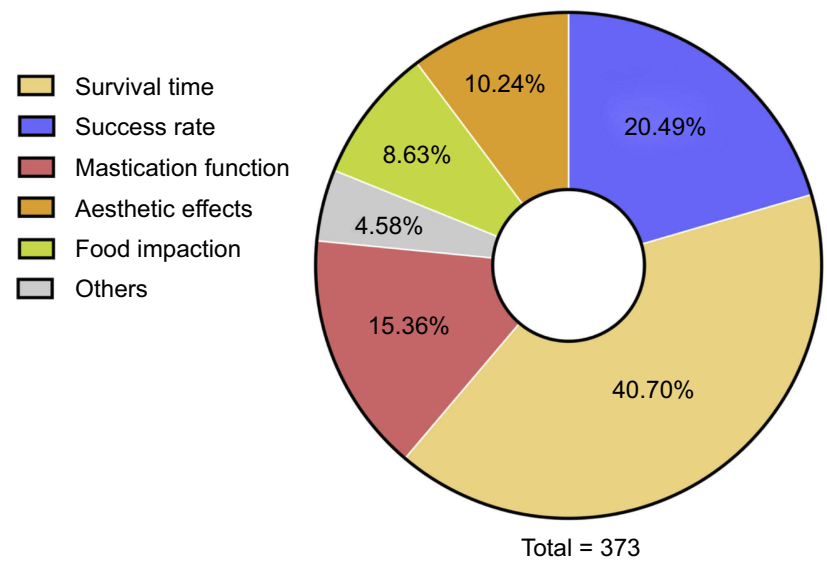

Figure 3 The distribution of responses to the open-ended question. The openended question at the bottom of the OIIP-Q was "what was the most concern aspect that affected your satisfaction in the implant treatment?" $N=373$.

On the other hand, some patients with inaccurate perceptions and unrealized expectations found it difficult to achieve excellent treatment results for dental implants, ${ }^{36}$ so it is important for these patients to establish practical desires of implant treatment in a reasonable and efficient communication way.

\section{Conclusion}

The results of this study showed that bone augmentation and the period of teeth loss were correlative factors affecting patient satisfaction, and the success rate and survival time of implants were the two important considerations for patients with dental implants. As a result, it is essential to raise the general awareness of oral hygiene as early as possible and optimize dental implant therapeutic processes as much as possible, both of which are conducive to enhancing patient satisfaction with dental implant surgery in the stomatological hospital.

\section{Acknowledgments}

The authors are grateful for grants from the National Natural Science Foundation of China (81371680 and 81571800 ) and the Foundation for Development of Science and Technology of Nanjing (201803036). They acknowledge the kind support of Guohua Xia and $\mathrm{Yu}$ Zhuang for language editing.

\section{Disclosure}

The authors declare that they have no competing interests in this work.

\section{References}

1. Alam MK, Rahman SA, Basri R, Tt SY, Si-Jie JW, Saha S. Dental implants-perceiving patients' satisfaction in relation to clinical and electromyography study on implant patients. PloS One. 2015;10(10): e0140438. doi:10.1371/journal.pone.0140438

2. Beikler T, Flemmig TF. EAO consensus conference: economic evaluation of implant-supported prostheses. Clin Oral Implants Res. 2015;26(Suppl 11):57-63. doi:10.1111/clr.12630

3. Levin L, Sadet P, Grossmann Y. A retrospective evaluation of 1,387 single-tooth implants: a 6-year follow-up. J Periodontol. 2006;77 (12):2080-2083. doi:10.1902/jop.2006.060220

4. Bidra AS, Tischler M, Patch C. Survival of 2039 complete arch fixed implant-supported zirconia prostheses: A retrospective study. $J$ Prosthet Dent. 2018;119(2):220-224. doi:10.1016/j.prosdent.2017. 05.004

5. Niedermaier R, Stelzle F, Riemann M, Bolz W, Schuh P, Wachtel H. Implant-supported immediately loaded fixed full-arch dentures: evaluation of implant survival rates in a case cohort of up to 7 years. Clin Implant Dent Relat Res. 2017;19(1):4-19. doi:10.1111/cid.12421

6. Yao J, Tang H, Gao XL, McGrath C, Mattheos N. Patients' expectations to dental implant: a systematic review of the literature. Health Qual Life Outcomes. 2014;12:153. doi:10.1186/ s12955-014-0153-9

7. Jayasinghe RM, Perera J, Jayasinghe V, et al. Awareness, attitudes, need and demand on replacement of missing teeth among a group of partially dentate patients attending a University Dental Hospital. BMC Res Notes. 2017;10(1):334. doi:10.1186/ s13104-017-2655-0

8. Olmedo-Gaya MV, Manzano-Moreno FJ, Canaveral-Cavero E, de Dios Luna-Del Castillo J, Vallecillo-Capilla M. Risk factors associated with early implant failure: A 5-year retrospective clinical study. J Prosthet Dent. 2016;115(2):150-155. doi:10.1016/j. prosdent.2015.07.020

9. Pektas O, Tonuk E. Mechanical design, analysis, and laboratory testing of a dental implant with axial flexibility similar to natural tooth with periodontal ligament. Proc Inst Mech Eng H. 2014;228 (11):1117-1125. doi:10.1177/0954411914557713

10. Liaw K, Delfini RH, Abrahams JJ. Dental implant complications. Semin Ultrasound CT MR. 2015;36(5):427-433. doi:10.1053/j. sult.2015.09.007

11. Gomez-de Diego R, Cutando-Soriano A, Montero-Martin J, PradosFrutos JC, Lopez-Valverde A. State anxiety and depression as factors modulating and influencing postoperative pain in dental implant surgery. A prospective clinical survey. Med Oral Patol Oral Cir Bucal. 2014;19(6):e592-e597.

12. Kuroi R, Minakuchi H, Hara ES, et al. A risk factor analysis of accumulated postoperative pain and swelling sensation after dental implant surgery using a cellular phone-based real-time assessment. $J$ Prosthodont Res. 2015;59(3):194-198. doi:10.1016/j.jpor.2015. 05.003

13. Hongxing L, List T, Nilsson IM, Johansson A, Astrom AN. Validity and reliability of OIDP and OHIP-14: a survey of Chinese high school students. BMC Oral Health. 2014;14:158. doi:10.1186/14726831-14-90

14. Ke P, Jiang F, Wu D, et al. A third-party investigation of inpatient satisfaction with a tertiary hospital in People's Republic of China. Patient Prefer Adherence. 2018;12:2027-2037. doi:10.2147/PPA. $\mathrm{S} 176471$

15. Lee CT, Zhang S, Leung YY, Li SK, Tsang CC, Chu CH. Patients` satisfaction and prevalence of complications on surgical extraction of third molar. Patient Prefer Adherence. 2015;9:257-263. doi:10.2147/ PPA.S76236

16. Besford JN, Sutton AF. Aesthetic possibilities in removable prosthodontics. Part 1: the aesthetic spectrum from perfect to personal. $\mathrm{Br}$ Dent J. 2018;224(1):15-19. doi:10.1038/sj.bdj.2018.2 
17. Reissmann DR, Poulopoulos G, Durham J. Patient perceived burden of implant placement compared to surgical tooth removal and apicectomy. $J$ Dent. 2015;43(12):1456-1461. doi:10.1016/j. jdent.2015.10.012

18. Cosola S, Marconcini S, Giammarinaro E, Poli GL, Covani U, Barone A. Oral health-related quality of life and clinical outcomes of immediately or delayed loaded implants in the rehabilitation of edentulous jaws: a retrospective comparative study. Minerva Stomatol. 2018;67 (5):189-195. doi:10.23736/S0026-4970.18.04134-1

19. Topcu AO, Yamalik N, Guncu GN, et al. Implant-site related and patient-based factors with the potential to impact patients' satisfaction, quality of life measures and perceptions toward dental implant treatment. Implant Dent. 2017;26(4):581-591. doi:10.1097/ID.000 0000000000623

20. Adler L, Liedholm E, Silvegren M, Modin C, Buhlin K, Jansson L. Patient satisfaction 8-14 years after dental implant therapy - a questionnaire study. Acta Odontol Scand. 2016;74(5):423-429. doi:10.1080/00016357.2016.1177661

21. Becker W, Hujoel P, Becker BE, Wohrle P. Dental implants in an aged population: evaluation of periodontal health, bone loss, implant survival, and quality of life. Clin Implant Dent Relat Res. 2016;18 (3):473-479. doi:10.1111/cid.12340

22. Angkaew C, Serichetaphongse P, Krisdapong S, Dart MM, Pimkhaokham A. Oral health-related quality of life and esthetic outcome in single anterior maxillary implants. Clin Oral Implants Res. 2017;28(9):1089-1096. doi:10.1111/clr.12922

23. Moghadam M, Dias R, Kuyinu E, Ferguson MB, Mucciolo T, Jahangiri L. Predoctoral fixed implant patient satisfaction outcome and challenges of a clinical implant competency. J Dent Educ. 2012;76(4):437-442.

24. Erkapers M, Segerstrom S, Ekstrand K, Baer RA, Toljanic JA, Thor A. The influence of immediately loaded implant treatment in the atrophic edentulous maxilla on oral health related quality of life of edentulous patients: 3-year results of a prospective study. Head Face Med. 2017;13(1):21. doi:10.1186/s13005-017-0154-0

25. Kim Y, Oh TJ, Misch CE, Wang HL. Occlusal considerations in implant therapy: clinical guidelines with biomechanical rationale. Clin Oral Implants Res. 2005;16(1):26-35. doi:10.1111/j.16000501.2004.01067.x

26. Hingsammer L, Pommer B, Furhauser R, Mailath-Pokorny G, Haas R, Busenlechner D. Single tooth implants in the esthetic zone following a two-stage all flapless approach: A retrospective analysis. Clin Implant Dent Relat Res. 2018. doi:10.1111/cid.12669
27. Noelken R, Moergel M, Kunkel M, Wagner W. Immediate and flapless implant insertion and provisionalization using autogenous bone grafts in the esthetic zone: 5-year results. Clin Oral Implants Res. 2018;29(3):320-327. doi:10.1111/clr.13119

28. D‘Haese J, Ackhurst J, Wismeijer D, De Bruyn H, Tahmaseb A. Current state of the art of computer-guided implant surgery. Periodontol 2000. 2017;73(1):121-133. doi:10.1111/prd.12175

29. Nedir R, Nurdin N, Abi Najm S, El Hage M, Bischof M. Short implants placed with or without grafting into atrophic sinuses: the 5-year results of a prospective randomized controlled study. Clin Oral Implants Res. 2017;28(7):877-886. doi:10.1111/clr.12893

30. Zhou N, Dong H, Zhu Y, Liu H, Zhou N, Mou Y. Analysis of implant loss risk factors especially in maxillary molar location: a retrospective study of 6977 implants in Chinese individuals. Clin Implant Dent Relat Res. 2019;21(1):138-144. doi:10.1111/cid.12697

31. Rammelsberg P, Mahabadi J, Eiffler C, Koob A, Kappel S, Gabbert O. Radiographic monitoring of changes in bone height after implant placement in combination with an internal sinus lift without graft material. Clin Implant Dent Relat Res. 2015;17(Suppl 1):e267-e274. doi:10.1111/cid.12138

32. Friberg B. Bone augmentation for single tooth implants: a review of the literature. Eur J Oral Implantol. 2016;9(Suppl 1):S123-S134.

33. Tepper G, Haas R, Mailath G, et al. Representative marketingoriented study on implants in the Austrian population. I. Level of information, sources of information and need for patient information. Clin Oral Implants Res. 2003;14(5):621-633.

34. Masaki C, Nakamoto T, Mukaibo T, Kondo Y, Hosokawa R. Strategies for alveolar ridge reconstruction and preservation for implant therapy. $J$ Prosthodont Res. 2015;59(4):220-228. doi:10.1016/j.jpor.2015.04.005

35. de Lima EA, Dos Santos MB, Marchini L. Patients' expectations of and satisfaction with implant-supported fixed partial dentures and single crowns. Int J Prosthodont. 2012;25(5):484-490.

36. Yao J, Li M, Tang H, et al. What do patients expect from treatment with dental implants? Perceptions, expectations and misconceptions: a multicenter study. Clin Oral Implants Res. 2017;28(3):261-271. doi: $10.1111 /$ clr. 12793

\section{Publish your work in this journal}

Patient Preference and Adherence is an international, peer-reviewed, open access journal that focusing on the growing importance of patient preference and adherence throughout the therapeutic continuum. Patient satisfaction, acceptability, quality of life, compliance, persistence and their role in developing new therapeutic modalities and compounds to optimize clinical outcomes for existing disease states are major areas of interest for the journal. This journal has been accepted for indexing on PubMed Central. The manuscript management system is completely online and includes a very quick and fair peer-review system, which is all easy to use. Visit http:// www.dovepress.com/testimonials.php to read real quotes from published authors. 